Research paper

\title{
Microstructure of carbon nitride affecting synergetic photocatalytic activity: Hydrogen bonds vs. structural defects
}

\author{
Huachun Lan ${ }^{\mathrm{a}}$, Lili Li ${ }^{\mathrm{a}, \mathrm{c}}$, Xiaoqiang An ${ }^{\mathrm{a}, *}$, Fei Liu ${ }^{\mathrm{c}}$, Cuibai Chen $^{\mathrm{c}}$, Huijuan Liu ${ }^{\mathrm{b}, \mathrm{d}}$, \\ Jiuhui $Q u^{\mathrm{a}, \mathrm{d}}$ \\ a Key Laboratory of Drinking Water Science and Technology, Research Center for Eco-Environmental Sciences, Chinese Academy of Sciences, Beijing, \\ 100085, China \\ b State Key Laboratory of Environmental Aquatic Chemistry, Research Center for Eco-Environmental Sciences, Chinese Academy of Sciences, Beijing, 100085, \\ China \\ ${ }^{c}$ China University of Geosciences, 100083, Beijing, PR China \\ d University of Chinese Academy of Sciences, Beijing 100049, China
}

\section{A R T I C L E I N F O}

\section{Article history:}

Received 31 August 2016

Received in revised form 29 October 2016

Accepted 12 November 2016

Available online 14 November 2016

\section{Keyword:}

Carbon nitride

Hydrogen bonds

Microstructure

Structural defects

Synergetic reactions

\begin{abstract}
A B S T R A C T
Carbon nitride has emerged as one of the most attractive materials for developing photocatalysts with low cost, high efficiency and structural stability. However, fast charge recombination caused intrinsically by the $\pi-\pi$ conjugated electronic system severely limits its photocatalytic performance. Constructing carbon nitride photocatalysts with modulated electronic structures is thus a promising but challenging task. In this paper, carbon nitride with different microstructural features, such as degree of polymerization, hydrogen bonds, bandgap, structural defects and ratio of $\mathrm{C} / \mathrm{N}$, were synthesized by polymerization of different types of nitrogen-rich precursors. Synergetic reactions were rationally designed for hydrogen production and the efficient and simultaneous removal of multiple contaminants, using carbon nitrides as metal-free photocatalysts. The significant impact of hydrogen bonds on synergetic photocatalysis was comprehensively demonstrated. With the smallest amount of hydrogen bonds, carbon nitride derived from urea exhibited fast charge transfer between interlayers, which is a prerequisite for superior photoactivity. By contrast, the polymerization of melamine and cyanamide was favorable for the formation of abundant hydrogen bonds and intrinsic vacancy defects. It was found that the coexistence of nitrogen deficiency and oxygen-doped microstructures could facilitate the activation of oxygen molecules, and thereby contributed to their moderate photoactivity. This research provides fundamental insights into the microstructural engineering of carbon nitride for high-performance synergetic applications.
\end{abstract}

(C) 2016 Published by Elsevier B.V.

\section{Introduction}

To date, the exploration of abundant, sustainable and efficient metal-free photocatalytic materials is especially attractive but challenging [1]. Since Wang and co-workers reported the photoactivity of polymeric graphitic carbon nitride $\left(\mathrm{g}-\mathrm{C}_{3} \mathrm{~N}_{4}\right)$, many efforts have been made to investigate its environmental and energy applications, such as $\mathrm{H}_{2}$ evolution, $\mathrm{CO}_{2}$ reduction, pollutant degradation and $\mathrm{H}_{2} \mathrm{O}_{2}$ production [2-8]. As a prospective organic semiconductor, $\mathrm{g}-\mathrm{C}_{3} \mathrm{~N}_{4}$ possesses the characteristics of excellent thermal and chemical stability, cost effectiveness, easy preparation and relatively small bandgap $(2.7 \mathrm{eV})$ for visiblelight-driven photocatalysis [9]. For high-performance applications, various strategies, including morphology control, metal/non-metal

\footnotetext{
* Corresponding author.

E-mail address: xqan@ressc.ac.cn (X. An).
}

doping, co-catalyst deposition and creation of heterostructures, have also been developed to modify $\mathrm{g}-\mathrm{C}_{3} \mathrm{~N}_{4}$ to improve its charge separation efficiency [10-18].

However, a fundamental understanding of the effect of carbon nitride microstructure on photocatalytic activity is still lacking. For example, several groups found that crystalline carbon nitride showed superior visible-light photoactivity toward hydrogen evolution $[19,20]$. In contrast, significantly enhanced activity of amorphous and less-crystalline carbon nitride has also been reported recently $[21,22]$. The presence of intrinsic structural defects has usually complicated this issue considerably. Based on previous reports, improved photocatalytic performance of carbon nitride can be achieved either through increasing structural defects (nitrogen or carbon vacancies) or decreasing sp2 nitrogen defects $[23,24]$. The discrepancies between these results largely depend on the diverse range of nitrogen-rich organic precursors that have been utilized for the preparation of carbon nitride through thermal polymerization. Thus, investigating the effect of the precursor 
on the microstructure and photoactivity is not only of scientific significance for a comprehensive understanding of carbon nitride architectures, but also technically important for the design of highefficiency photocatalysts.

In addition to the strategy of material design, synergetic reaction is another promising way to improve photocatalytic efficiency. Generally, photo-induced electrons can contribute to photoreduction reactions, while separated holes play an important role in photooxidation reactions. The accelerated consumption of opposite-charge carriers undoubtedly results in the enhancement of overall efficiency $[25,26]$. A typical prototype for this is the widespread utilization of hole or electron scavengers during photocatalytic $\mathrm{H}_{2}$ or $\mathrm{O}_{2}$ evolution. Recently, this approach has also been demonstrated by selectively converting $\mathrm{H}_{2} \mathrm{~S}$ and $\mathrm{O}_{2}$ into $\mathrm{S}$ and $\mathrm{H}_{2} \mathrm{O}_{2}$ [27]. The rational design of synergetic reactions during water treatment is also highly desirable, either for the efficient removal of environmental pollutants or simultaneous energy production. Thereafter, it is of great importance to develop high-efficiency carbon nitride as a metal-free photocatalyst for highly efficient synergetic applications [28].

Unfortunately, the relationship between carbon nitride microstructure and synergetic reactions remains largely unknown. It is of great importance to rationally design synergetic photocatalytic reactions and evaluate the effect of carbon nitride microstructure on the reaction applicability. 5-Sulfosalicylic acid (SSA) is an important chemical that is widely used in pharmaceutical production, metal plating, pigment manufacturing and leather tanning. Industrial wastewater including SSA can bring about severe environmental problems because of its substantial threats to human health. This issue is often complicated due to the coexistence of heavy metals, such as highly toxic hexavalent chromium $\mathrm{Cr}(\mathrm{VI})$. The technical requirements for low-cost and efficient elimination of contaminants inspired us to investigate the great potential of metal-free carbon nitride for synergetic photocatalysis. Through coupling photooxidation of SSA with photoreduction of $\mathrm{Cr}(\mathrm{VI})$ or water, the removal of multiple contaminants or simultaneous hydrogen energy production can be reasonably expected.

In this study, metal-free $\mathrm{g}-\mathrm{C}_{3} \mathrm{~N}_{4}$ photocatalysts with different microstructures were obtained through thermal polymerization of different nitrogen-containing organic precursors. The impact of carbon nitride microstructure on the synergetic photocatalytic performance and associated reaction pathways was comprehensively evaluated, using SSA degradation $/ \mathrm{Cr}$ (VI) reduction and SSA degradation/hydrogen evolution as model reactions. Hydrogen bonds between polymeric melon strands contributed most to the efficiency of synergetic reactions, resulting in 3- and 8-fold improvements in contaminant removal and hydrogen production rates. It was also found that the successive formation of nitrogen vacancies and oxygen-doped structures were prerequisites for activating oxygen molecules, which provided new insights into defect engineering of carbon nitride for photocatalytic applications. Understanding the fundamental roles of hydrogen bonds and structural defects on the synergetic reaction mechanism could provide guiding principles for the design of high performance carbon nitride, as metal-free photocatalysts for environmental remediation.

\section{Experimental section}

\subsection{Synthesis of $g-C_{3} N_{4}$}

Different precursors purchased from J\&K (Shanghai, China), including cyanamide, melamine and urea, were used to fabricate pure $\mathrm{g}-\mathrm{C}_{3} \mathrm{~N}_{4}$ with different microstructures through a simple ther- mal polycondensation method [29]. In a typical procedure, a certain amount of precursor powder was put into a crucible with a loose cover and heated in static air by a muffle furnace at $550^{\circ} \mathrm{C}$ for $4 \mathrm{~h}$ (heating rate: $5^{\circ} \mathrm{C} / \mathrm{min}$ ). After cooling to room temperature, the yellow products were collected and ground into powders with a ceramic mortar for further use. For convenience of description, the products synthesized from urea, cyanamide and melamine are denoted as g- $\mathrm{C}_{3} \mathrm{~N}_{4}-\mathrm{U}, \mathrm{g}-\mathrm{C}_{3} \mathrm{~N}_{4}-\mathrm{C}$ and g- $\mathrm{C}_{3} \mathrm{~N}_{4}-\mathrm{M}$, respectively.

\subsection{Catalyst characterizations}

The phase structure of carbon nitride was studied using a Bruker D8 Advance X-ray diffractometer (XRD). The morphology of products was observed using a Hitachi H-800 Transmission electron microscope (TEM). Fourier transform infrared spectra (FT-IR) were recorded on a Bruker Tenson 27 FT-IR spectrometer. X-ray photoelectron spectroscopy (XPS) measurements were carried out on an AXIS-Ultra instrument (Kratos Analytical, UK) using monochromatic Al K $\alpha$ radiation. UV-vis diffuse reflectance spectra (DRS) were collected by a UV-vis-NIR spectrometer (Varian, USA). Electron spin resonance (ESR) analysis was obtained using a Bruker electron paramagnetic resonance spectrometer (ESP 300E).

\subsection{Evaluation of photocatalytic properties}

Synergetic reactions were used to evaluate the photocatalytic activity of carbon nitride. For the simultaneous removal of organic pollutants and toxic $\mathrm{Cr}(\mathrm{VI}), 50 \mathrm{mg}$ portions of photocatalysts were added into $100 \mathrm{~mL}$ deionized water solution with $10 \mathrm{mg} / \mathrm{L} \mathrm{Cr}(\mathrm{VI})$ and $40 \mathrm{mg} / \mathrm{L} \mathrm{SSA}$, which were prepared using $\mathrm{K}_{2} \mathrm{CrO}_{4}(>99 \%)$ and 5-Sulfosalicylic acid (>99\%) purchased from Sinopharm Chemical Reagent Co., Ltd., (China). The pH was adjusted to 2 with $0.2 \mathrm{wt} \% \mathrm{HCl}$ and $0.1 \mathrm{~mol} / \mathrm{L} \mathrm{NaOH}$. Prior to irradiation, the suspension was ultrasonicated and magnetically stirred in the dark for $2 \mathrm{~h}$ to ensure uniform dispersion and adsorption/desorption equilibrium. Then, the suspension was irradiated by a $300 \mathrm{~W}$ Xe lamp. At given time intervals, $1.5 \mathrm{~mL}$ liquid samples were collected and filtered by microporous filtration membranes $(0.45 \mu \mathrm{m}$, PTFE) for chemical analysis. According to the 1,5-diphenylcarbazid photometric method (Chinese National Standard Procedure, GB7467-87), the concentration of $\mathrm{Cr}(\mathrm{VI})$ was determined by measuring the absorption of the pollutant solution at $540 \mathrm{~nm}$, using a UV/Vis spectrophotometer (Hitachi, Japan). The SSA concentration was determined by a high-performance liquid chromatograph (HPLC) (Agilent, USA) [30]. The reduction or removal ratio of $\mathrm{Cr}$ (VI) and SSA were calculated by $\mathrm{C} / \mathrm{C}_{0}$, where $\mathrm{C}$ is the concentration of $\mathrm{Cr}(\mathrm{VI})$ or SSA at each irradiated time interval and $C_{0}$ is the initial concentration of $\mathrm{Cr}(\mathrm{VI})$ or SSA.

The potential application of a synergetic strategy for simultaneous removal of organic pollutants and hydrogen energy production was also investigated. Photocatalytic $\mathrm{H}_{2}$ evolution was conducted in a Pyrex reaction vessel connected to a glassclosed-gas circulation system $[31,32]$. For each reaction, $50 \mathrm{mg}$ of carbon nitride was dispersed and sonicated for $20 \mathrm{~min}$ in $100 \mathrm{~mL}$ aqueous solution The concentration of SSA contaminant was $50 \mathrm{mg} / \mathrm{L}$. $\mathrm{H}_{2} \mathrm{PtCl}_{6}$ dissolved in the reactant solution was used to photodeposite $3 \mathrm{wt} \%$ of Pt co-catalyst onto the carbon nitride. Then the reactor was sealed and evacuated several times to remove air before being irradiated under a $300 \mathrm{~W}$ Xe lamp. The temperature of the reaction solution was carefully controlled to about $5{ }^{\circ} \mathrm{C}$ throughout the experiments. The amount of evolved $\mathrm{H}_{2}$ was analyzed by gas chromatography (GC-7900) with argon as carrier gas. 


\subsection{Analysis of photocatalytic mechanism}

To clarify the mechanism of synergetic photocatalytic reactions, active trapping experiments on the photocatalytic degradation of SSA were conducted. In a typical experiment, $50 \mathrm{mg}$ carbon nitride derived from different precursors was added into $100 \mathrm{~mL}$ solution with $40 \mathrm{mg} / \mathrm{L}$ SSA. After the addition of different radical scavengers, photodegradation reactions were carried out according to the above method. Basically, methanol and tert-butanol were used as $\mathrm{h}^{+}$and $\bullet \mathrm{OH}$ scavengers with the concentration of $4 \mathrm{wt} \%$ to ensure the total capture of radicals. The formation of $\bullet^{-} \mathrm{O}_{2}^{-}$was inhibited by purging the solution with argon (gas flow: $100 \mathrm{~mL} / \mathrm{min}$ ). To verify the presence of active oxygen radicals, the ESR signals of radicals spin-trapped by 5,5-dimethyl-1-pyrrolin-N-oxide (DMPO) were recorded during the photodegradation reactions $[7,33]$.

\section{Results and discussion}

\subsection{Effect of precursor on the microstructure of carbon nitride}

The crystal structure of carbon nitride derived from different precursors was first studied by XRD. As shown in Fig. 1a, all samples exhibit similar diffraction peaks, suggesting similar crystal structures. The (100) diffraction peak at $13.1^{\circ}$ is associated with hydrogen bonds maintaining interlayer long-range atomic order between tri-s-triazine units. The typical (002) peak centered about $27.3^{\circ}$ is ascribed to the van der Waals force controlling interlayer stacking [34]. As g- $\mathrm{C}_{3} \mathrm{~N}_{4}-\mathrm{U}$ possesses the weakest intensity for the 13.1 peak and a widened peak at $27.3^{\circ}$, it can be easily deduced that carbon nitride polymers with the lowest amount of interlayer hydrogen bonds are formed during the polymerization of urea. Recently, it has been reported that the transport of charge carriers within the layer of carbon nitride could be facilitated by breaking hydrogen bonds between each polymeric melon strand. As a result, superior photoactivity is rationally expected for $\mathrm{g}-\mathrm{C}_{3} \mathrm{~N}_{4}-\mathrm{U}$. Some minor changes are also observed in the partially enlarged view of the (002) peak. Fig. 1b illustrates that $\mathrm{g}-\mathrm{C}_{3} \mathrm{~N}_{4}-\mathrm{U}$ possesses the smallest diffraction angle of $27.24^{\circ}$, indicating a slightly enlarged interlayer spacing of $0.328 \mathrm{~nm}$. In contrast, the corresponding peak of $\mathrm{g}-\mathrm{C}_{3} \mathrm{~N}_{4}-\mathrm{M}$ shifts to $27.5^{\circ}$, demonstrating the tight packing of nanosheets, with an interlayer distance of $0.323 \mathrm{~nm}$.

The molecular structure of carbon nitride photocatalysts derived from different precursors was analyzed by FTIR. As shown in Fig. 1c, the broad peaks ranging from 3000 to $3500 \mathrm{~cm}^{-1}$ can be ascribed to $-\mathrm{NH}$ and $-\mathrm{OH}$ stretches [6]. The strong bands in the $1200-1650 \mathrm{~cm}^{-1}$ region are assigned to the typical stretching vibration modes of $\mathrm{C}-\mathrm{N}$ heterocycles. The intensity ratio between $-\mathrm{NH}$ and $\mathrm{C}-\mathrm{N}$ heterocycles follows the order of melamine $>$ cyanamide $>$ urea, indicating the least $-\mathrm{NH}$ in $\mathrm{g}_{-} \mathrm{C}_{3} \mathrm{~N}_{4}$ $\mathrm{U}$ and therefore the highest degree of polymerization among the samples [4]. The sharp peak at approximately $810 \mathrm{~cm}^{-1}$ originates from the characteristic breathing mode of tri-s-triazine units. Based on the enlarged view in Fig. 1d, the corresponding peak of $g-\mathrm{C}_{3} \mathrm{~N}_{4}-\mathrm{U}$ is blue-shifted to $815 \mathrm{~cm}^{-1}$. The decrease of electron cloud density confirms the relatively lower amount of hydrogen bonds in g- $\mathrm{C}_{3} \mathrm{~N}_{4}-\mathrm{U}$, which agrees well with the XRD results.

The morphologies of the resulting samples were observed by TEM. As shown in Fig. 2, all types of g- $\mathrm{C}_{3} \mathrm{~N}_{4}$ exhibit a lamellar stacking structure with folded edges. Further observation suggests that the average size of the sheets is several tens of nanometers.

XPS measurements were undertaken to study the chemical valence state of the elements in $\mathrm{g}-\mathrm{C}_{3} \mathrm{~N}_{4}$. All the catalysts are mainly composed of $\mathrm{C}$ and $\mathrm{N}$ elements. The high-resolution $\mathrm{N} 1 \mathrm{~s}$ spectra in Fig. 3 can be decomposed into three Gaussian-Lorenzian peaks. According to the previous reports, the N1s core levels at
Table 1

The calculation of proton concentration and the ratio of $\mathrm{C} / \mathrm{N}$.

\begin{tabular}{llll}
\hline Ratio & $\mathrm{g}-\mathrm{C}_{3} \mathrm{~N}_{4}-\mathrm{U}$ & $\mathrm{g}-\mathrm{C}_{3} \mathrm{~N}_{4}-\mathrm{C}$ & $\mathrm{g}-\mathrm{C}_{3} \mathrm{~N}_{4}-\mathrm{M}$ \\
\hline Ratio (sp2 to sum of sp3 and $\left.\mathrm{C}-\mathrm{NH}_{\mathrm{X}}\right)$ & 3.83 & 1.68 & 2.06 \\
Ratio(C/N) & 0.79 & 0.82 & 0.83 \\
\hline
\end{tabular}

398.7, 399.7, and 400.9 eV correspond to sp2 $\mathrm{C}-\mathrm{N}-\mathrm{C}$, sp3 $\mathrm{N}-(\mathrm{C})_{3}$ and $\mathrm{C}-\mathrm{NH}_{\mathrm{x}}$, respectively $[4,35]$. For layered carbon nitride, both amine protons and those connected with hybridized sp3 nitrogen could contribute to the formation of hydrogen bonds. Therefore, the effect of precursor selection on the proton concentration in the microstructures was further evaluated. The ratio of sp2 $\mathrm{C}-\mathrm{N}-\mathrm{C}$ bonds to the sum of sp3 $\mathrm{N}-(\mathrm{C})_{3}$ and $\mathrm{C}-\mathrm{N}-\mathrm{H}_{\mathrm{X}}$ bonds is 3.83 for g- $\mathrm{C}_{3} \mathrm{~N}_{4}-\mathrm{U}$, and this value was much larger than that of 1.68 for $\mathrm{g}$ $\mathrm{C}_{3} \mathrm{~N}_{4}-\mathrm{C}$ and 2.06 for $\mathrm{g}-\mathrm{C}_{3} \mathrm{~N}_{4}-\mathrm{M}$ (Table 1 ). As the increased value represents a decreased content of protons, it is reasonably believed that $\mathrm{g}-\mathrm{C}_{3} \mathrm{~N}_{4}-\mathrm{C}$ possesses the largest amount of hydrogen bonds, while the lowest amount was found for $\mathrm{g}-\mathrm{C}_{3} \mathrm{~N}_{4}-\mathrm{U}$.

The effect of the precursor on the formation of structural defects, another important characteristic of carbon nitride microstructures, was further considered and compared with the results for hydrogen bonds. The atomic ratio of $\mathrm{C} / \mathrm{N}$ was evaluated by XPS. Generally, g- $\mathrm{C}_{3} \mathrm{~N}_{4}$-U presents the lowest value of 0.79 , which approaches that of 0.75 in stoichiometric $\mathrm{C}_{3} \mathrm{~N}_{4}$. The ratio of $\mathrm{C} / \mathrm{N}$ in $\mathrm{g}-\mathrm{C}_{3} \mathrm{~N}_{4}-$ $\mathrm{C}$ increases to 0.82 , and $\mathrm{g}-\mathrm{C}_{3} \mathrm{~N}_{4}$-M exhibits the largest value of 0.83 . Combined with the results of proton concentration, we can deduce that nitrogen atoms in $\mathrm{g}-\mathrm{C}_{3} \mathrm{~N}_{4}$-U mainly contribute to tris-triazineheptazine rings, instead of hydrogen bonds linked with protons. Therefore, the urea precursor results in a higher degree of polymerization in $\mathrm{g}-\mathrm{C}_{3} \mathrm{~N}_{4}-\mathrm{U}$, while melamine and cyanamide facilitate the formation of abundant nitrogen vacancies. The effect of vacancy defects on the microstructure of carbon nitride was further clarified. Fig. S1 shows the high-resolution O 1s XPS spectra of $\mathrm{g}-\mathrm{C}_{3} \mathrm{~N}_{4}-\mathrm{M}$ and $\mathrm{g}-\mathrm{C}_{3} \mathrm{~N}_{4}-\mathrm{C}$. Both spectra show core level peaks at about $532.9 \mathrm{eV}$, corresponding to adsorbed water on the surface. However, an additional peak around $530.5 \mathrm{eV}$ is also detected for g- $\mathrm{C}_{3} \mathrm{~N}_{4}-\mathrm{C}$, which agrees well with $\mathrm{C}=\mathrm{O}$ or $\mathrm{N}-\mathrm{C}-\mathrm{O}$ bonds in oxygendoped carbon nitride. The formation of oxygen-doped structures in $\mathrm{g}-\mathrm{C}_{3} \mathrm{~N}_{4}$-C can be further confirmed by the appearance of an FTIR peak at $1245 \mathrm{~cm}^{-1}$ (Fig. S2), which demonstrates the beneficial effect of nitrogen deficiency on oxygen doping during thermal polymerization [36]. However, a different trend is observed for $C_{3} N_{4}-M$, although abundant nitrogen vacancies are also detected. The possible reason for this phenomenon might be the relatively small interlayer distance $(0.323 \mathrm{~nm})$, which would inhibit the diffusion of oxygen molecules, with diameter of $0.296 \mathrm{~nm}$. The differences in structural defects between $\mathrm{g}_{-} \mathrm{C}_{3} \mathrm{~N}_{4}-\mathrm{C}$ and g- $\mathrm{C}_{3} \mathrm{~N}_{4}$-M suggest the possibility of different effects on synergetic performance.

ESR measurements were carried out to obtain more information on structural defects in different types of carbon nitride [37]. As shown in Fig. 4, all samples show asymmetric signal lines centered at the $g$ value of 2.001 , which can be ascribed to the unpaired electrons on the carbon atoms of heptazine rings [38]. The type of precursor used exerts an obvious influence on the structural defects of carbon nitride. The ESR signal intensity of $\mathrm{g}-\mathrm{C}_{3} \mathrm{~N}_{4}-\mathrm{U}$ is very weak because of the higher degree of polymerization. However, the other two samples exhibit strong spin intensities, revealing high concentrations of delocalized electrons. It has been reported that both carbon vacancies and nitrogen vacancies can contribute to the improved photoactivity of carbon nitride [39]. Different from the decreased $\mathrm{C} / \mathrm{N}$ ratio for $\mathrm{C}_{3} \mathrm{~N}_{4}$ with carbon vacancies, carbon nitride photocatalysts with defective structures exhibit relatively higher $\mathrm{C} / \mathrm{N}$ ratio than $\mathrm{g}-\mathrm{C}_{3} \mathrm{~N}_{4}-\mathrm{U}(0.79)$ in our work [40]. Both the characteristics of nitrogen deficiency and stronger ESR signals indicate the presence of abundant nitrogen vacancies in the microstructures of 

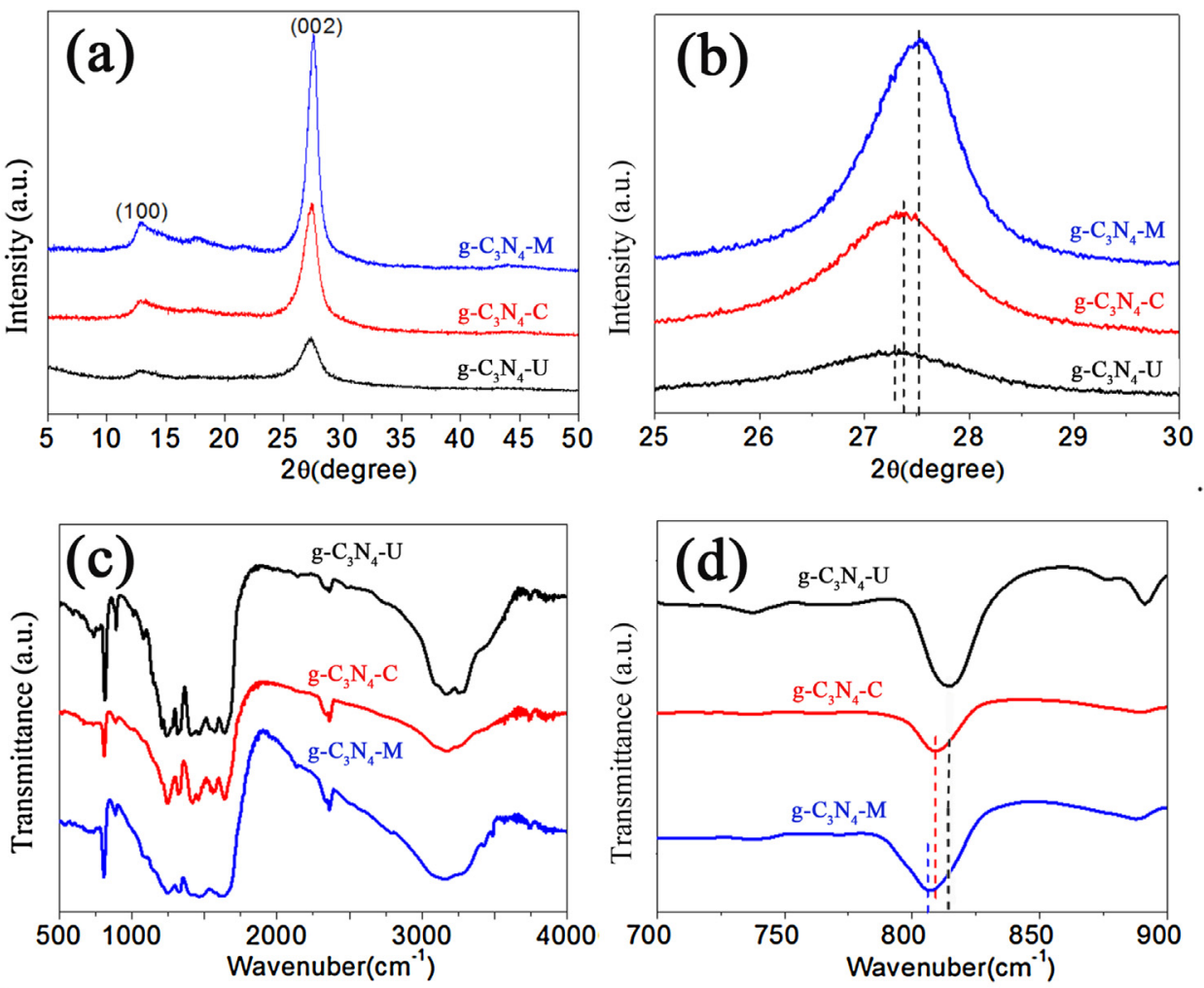

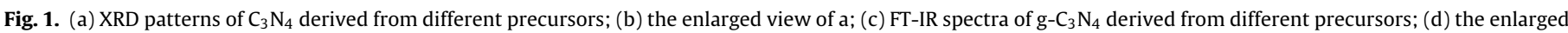
view of $c$.

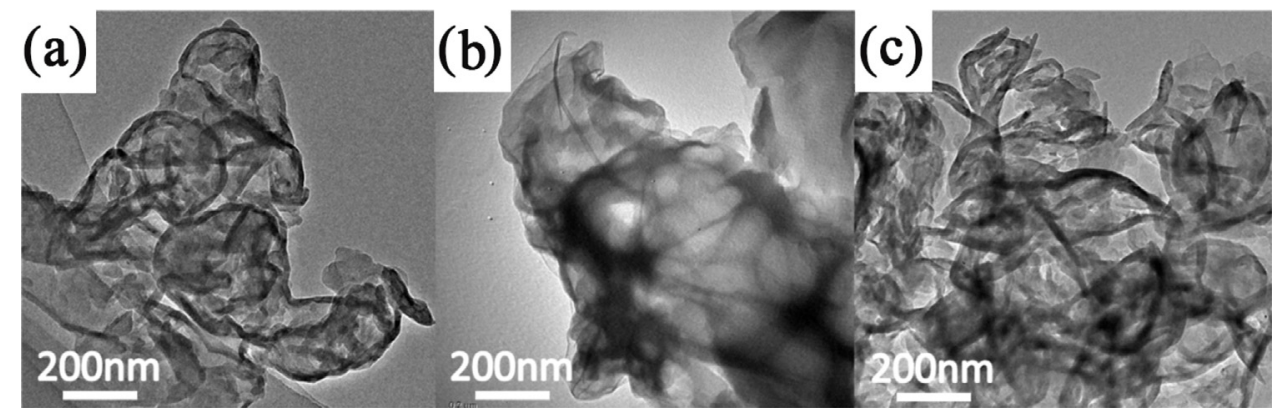

Fig. 2. TEM images of $g-C_{3} N_{4}-U(a), g-C_{3} N_{4}-C$ (b) and $g-C_{3} N_{4}-M(c)$.
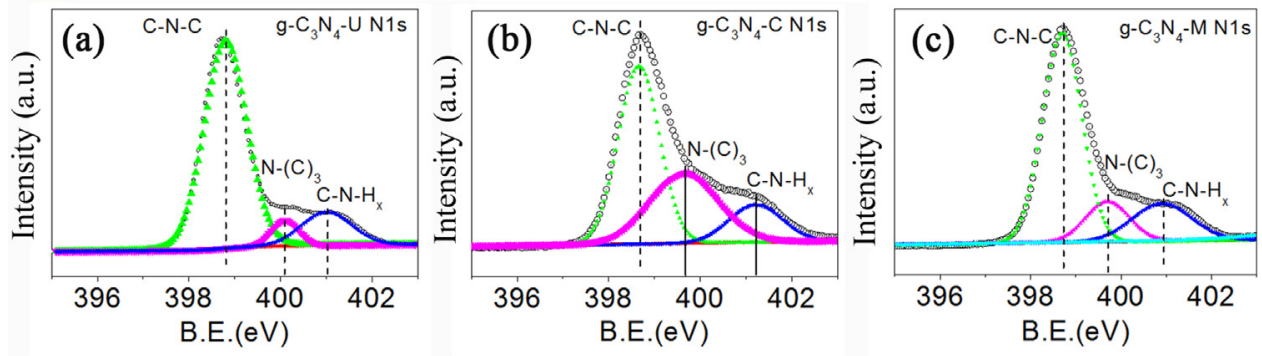

Fig. 3. N1s XPS spectra of $g-C_{3} N_{4}$ derived from different precursors.

g- $\mathrm{C}_{3} \mathrm{~N}_{4}-\mathrm{C}$ and $\mathrm{g}-\mathrm{C}_{3} \mathrm{~N}_{4}-\mathrm{M}$. It is expected that these defect sites have significant effects on the separation and transfer of charge carriers during photocatalysis.

Besides hydrogen bonds and structural defects, several other characteristics of carbon nitride microstructures were considered. Optical absorption, the most commonly studied factor for photocatalytic applications, was evaluated by UV-vis diffuse reflection spectroscopy (DRS). The absorption edge of $\mathrm{g}-\mathrm{C}_{3} \mathrm{~N}_{4}-\mathrm{U}$ is $450 \mathrm{~nm}$, indicating its capability for visible light absorption. The DRS spectra of g- $\mathrm{C}_{3} \mathrm{~N}_{4}-\mathrm{M}$ and $\mathrm{g}-\mathrm{C}_{3} \mathrm{~N}_{4}-\mathrm{C}$ show a red-shifted optical absorption threshold from $450 \mathrm{~nm}$ to approximately $500 \mathrm{~nm}$. This is consistent with the color change in the digital images of different photocatalysts, which are presented in the inset of Fig. 5a. As can be seen, the color of $\mathrm{g}-\mathrm{C}_{3} \mathrm{~N}_{4}-\mathrm{U}$ is light yellow, while it changes to yellow 


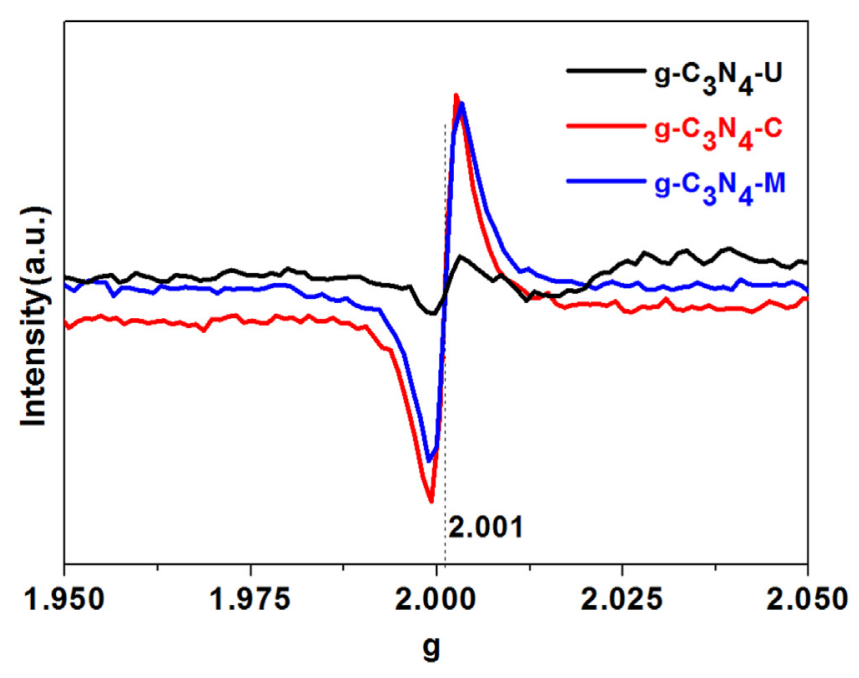

Fig. 4. ESR spectra of $g-C_{3} N_{4}$ derived from different precursors.

for g- $\mathrm{C}_{3} \mathrm{~N}_{4}-\mathrm{C}$ and $\mathrm{g}-\mathrm{C}_{3} \mathrm{~N}_{4}-\mathrm{M}$. Therefore, the precursors of melamine and cyanamide can result in the formation of carbon nitride with stronger light absorption ability, while the poorest absorption is achieved for the material prepared from the urea precursor.

Fig. S3a shows the $\mathrm{N}_{2}$ adsorption-desorption isotherms and the corresponding Barrett-Joyner-Halenda pore size distribution curves of different products. All types of carbon nitride show type IV isotherms. The appearance of hysteresis loops is associated with the porous structures in the aggregates of plate-like particles [41]. The BET specific surface area of $\mathrm{C}_{3} \mathrm{~N}_{4}$ follows the order of $\mathrm{g}-\mathrm{C}_{3} \mathrm{~N}_{4}$ $\mathrm{U}\left(95.0 \mathrm{~m}^{2} \mathrm{~g}^{-1}\right)>\mathrm{g}-\mathrm{C}_{3} \mathrm{~N}_{4}-\mathrm{M}\left(16.5 \mathrm{~m}^{2} \mathrm{~g}^{-1}\right)>\mathrm{g}-\mathrm{C}_{3} \mathrm{~N}_{4}-\mathrm{C}\left(10.3 \mathrm{~m}^{2} \mathrm{~g}^{-1}\right)$. The pore size distribution of carbon nitride (Fig. S3b) further confirms the formation of mesoporous structures between packed layers. Both $\mathrm{g}-\mathrm{C}_{3} \mathrm{~N}_{4}-\mathrm{U}$ and g- $\mathrm{C}_{3} \mathrm{~N}_{4}-\mathrm{C}$ exhibit broad pore size distribution, in the range of $10-130 \mathrm{~nm}$. In contrast, the position of dominant peak is obviously left-shifted for $\mathrm{g}-\mathrm{C}_{3} \mathrm{~N}_{4}-\mathrm{M}$. It indicates the tight packing of carbon nitride nanosheets, which is consistent with the XRD results.

Thereafter, the band gap energy ( $\left.E_{g}\right)$ of carbon nitride was calculated by plots of $(\alpha h \gamma)^{1 / 2}$ vs photon energy. From Fig. $5 \mathrm{~b}$, the values are determined to be $2.68,2.36$ and $2.44 \mathrm{eV}$ for $\mathrm{g}-\mathrm{C}_{3} \mathrm{~N}_{4}-\mathrm{U}, \mathrm{g}-\mathrm{C}_{3} \mathrm{~N}_{4}-\mathrm{C}$ and $g-C_{3} \mathrm{~N}_{4}-\mathrm{M}$, respectively $[31,42]$. The valence band (VB) position of carbon nitride was determined by VB XPS, in order to determine the band structure of carbon nitride. As displayed in Fig. 6c, the valence band positions of $\mathrm{g}-\mathrm{C}_{3} \mathrm{~N}_{4}-\mathrm{U}$, g- $\mathrm{C}_{3} \mathrm{~N}_{4}-\mathrm{C}$ and $\mathrm{g}-\mathrm{C}_{3} \mathrm{~N}_{4}-\mathrm{M}$ are located at 2.0, 2.52 and $2.08 \mathrm{eV}$, respectively. Combined with the band gap energy of carbon nitride, the conduction band (CB) positions can be calculated. The band structure alignment of carbon nitride derived from different precursors is shown in Fig. 5d. Overall, metal-free photocatalysts with different microstructures can be synthesized through precursor selection. Compared to the commonly used melamine, polymerization of urea leads to the formation of carbon nitride with weak light absorption of visible light and relatively higher band energy levels.

\subsection{Effect of carbon nitride microstructure on the synergetic reactions}

Photooxidation of SSA and photoreduction of $\mathrm{Cr}(\mathrm{VI})$ were used first as synergetic reactions to evaluate the photocatalytic activity of carbon nitride polymers. As shown in Fig. 6, the adsorption of SSA and $\mathrm{Cr}(\mathrm{VI})$ onto the photocatalyst surface is negligible at adsorption equilibrium in the dark. No noticeable degradation of SSA or reduction of $\mathrm{Cr}(\mathrm{VI})$ is observed without the addition of carbon nitride polymers. The efficiencies of separate reactions and synergetic photocatalytic reactions were compared. g- $\mathrm{C}_{3} \mathrm{~N}_{4}-\mathrm{M}$, the most commonly used carbon nitride polymer, was used as a bench-
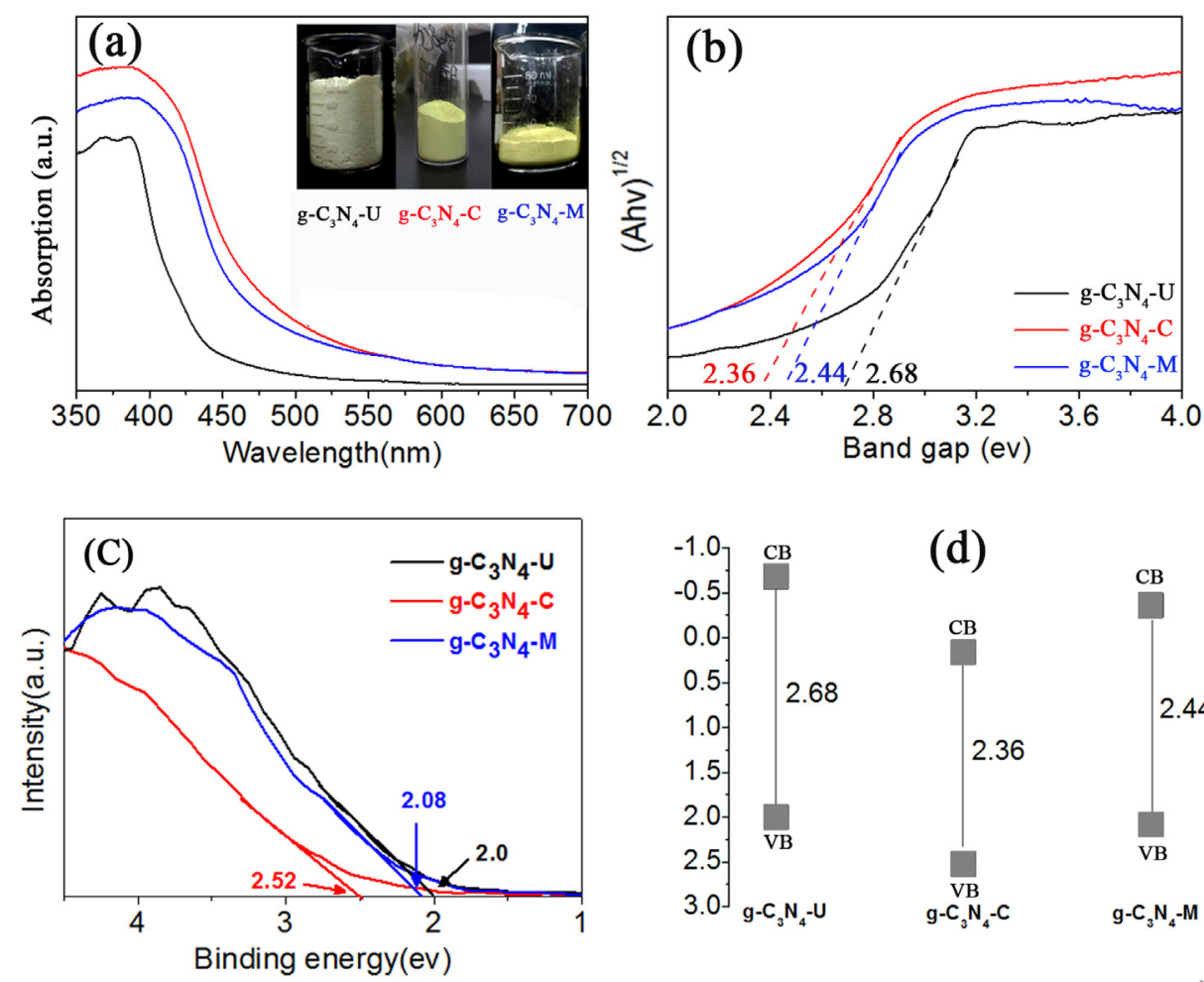

(d)

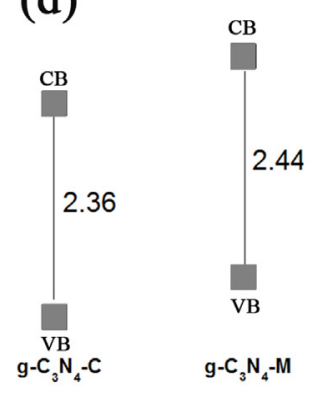

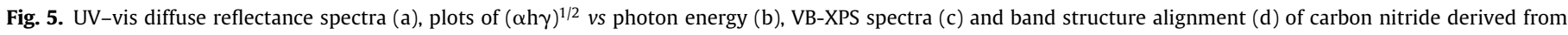
different precursors. 

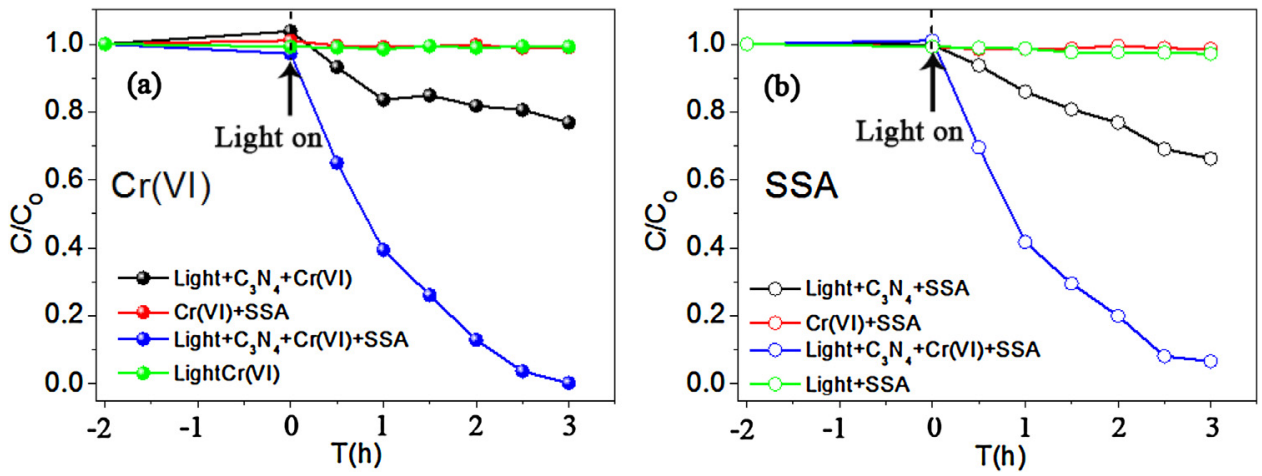

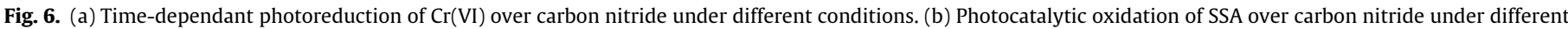
conditions.
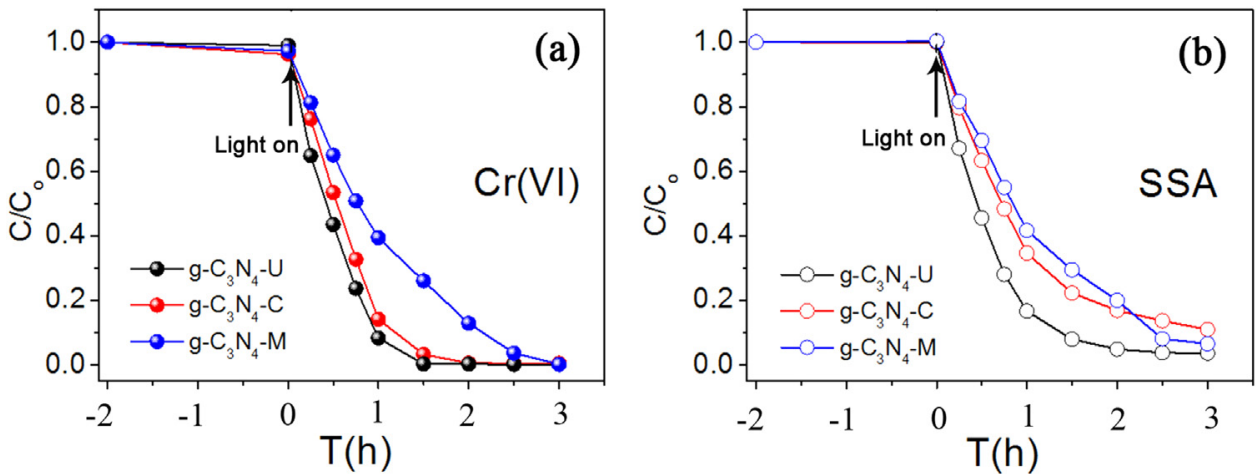

Fig. 7. The reducing ratio of $\mathrm{Cr}(\mathrm{VI})(\mathrm{a})$ and removal ratio of SSA (b) in the synergetic reaction over g- $\mathrm{C}_{3} \mathrm{~N}_{4}$ catalysts derived from different precursors.

mark. For the separate reactions, only $20 \% \mathrm{Cr}(\mathrm{VI})$ and $30 \%$ SSA could be reduced or removed after $3 \mathrm{~h}$ reaction. However, both significantly enhanced photooxidation and photoreduction activity was achieved through coupling the two separate reactions together. Under optimal conditions, more than $85 \%$ of the pollutants was reduced or removed within $1 \mathrm{~h}$, which is more than 3 times faster than the separate reactions. This indicates that poor charge separation ability is the rate-limiting factor for $g-\mathrm{C}_{3} \mathrm{~N}_{4}-\mathrm{M}$. Thus, the efficient and simultaneous treatment of different types of pollutants confirms the great potential of the synergetic strategy.

To study the effect of microstructure on the separate and synergetic reactions, carbon nitrides synthesized from different precursors were used as photocatalysts for the treatment of SSA and $\mathrm{Cr}(\mathrm{VI})$. Photoreduction of $\mathrm{Cr}(\mathrm{VI})$ and photocatalytic oxidation of SSA were separately carried out, using different carbon nitride as photocatalysts. As can be seen from Fig. S4, g- $\mathrm{C}_{3} \mathrm{~N}_{4}-\mathrm{U}$, with the lowest amount of hydrogen bonds, exhibits the highest activity for both SSA degradation and reduction of $\mathrm{Cr}(\mathrm{VI})$. Correspondingly, $\mathrm{g}-\mathrm{C}_{3} \mathrm{~N}_{4}-\mathrm{M}$, which is the most commonly used carbon nitride for photocatalytic hydrogen production, shows the poorest activity for photocatalytic environmental remediation. Similar results were also achieved for the simultaneous treatment of $\mathrm{Cr}(\mathrm{VI})$ and SSA as shown in Fig. 7. In the synergetic reactions, the overall reaction rates are significantly accelerated, as both $\mathrm{Cr}(\mathrm{VI})$ and SSA can be nearly completely reduced or removed within $1.5 \mathrm{~h}$ under irradiation. $\mathrm{g}-\mathrm{C}_{3} \mathrm{~N}_{4}-\mathrm{C}$ exhibits comparable ability for $\mathrm{Cr}(\mathrm{VI})$ reduction but moderate activity for SSA oxidation. After $1.5 \mathrm{~h}$ reaction, the removal ratio of SSA and reduction ratio of $\mathrm{Cr}(\mathrm{VI})$ over $\mathrm{g}_{-} \mathrm{C}_{3} \mathrm{~N}_{4}-\mathrm{U}$ were 1.6 and 1.4 times higher than those of $\mathrm{g}-\mathrm{C}_{3} \mathrm{~N}_{4}-\mathrm{M}$. In addition, the average apparent rate constant of $\mathrm{g}-\mathrm{C}_{3} \mathrm{~N}_{4}-\mathrm{C}$ is relatively higher than $\mathrm{g}-\mathrm{C}_{3} \mathrm{~N}_{4}$-M. During the late stage of photodegradation reaction, its slightly lower removal ratio of SSA indicates a complicated interactions in the defective structures. This indicates the

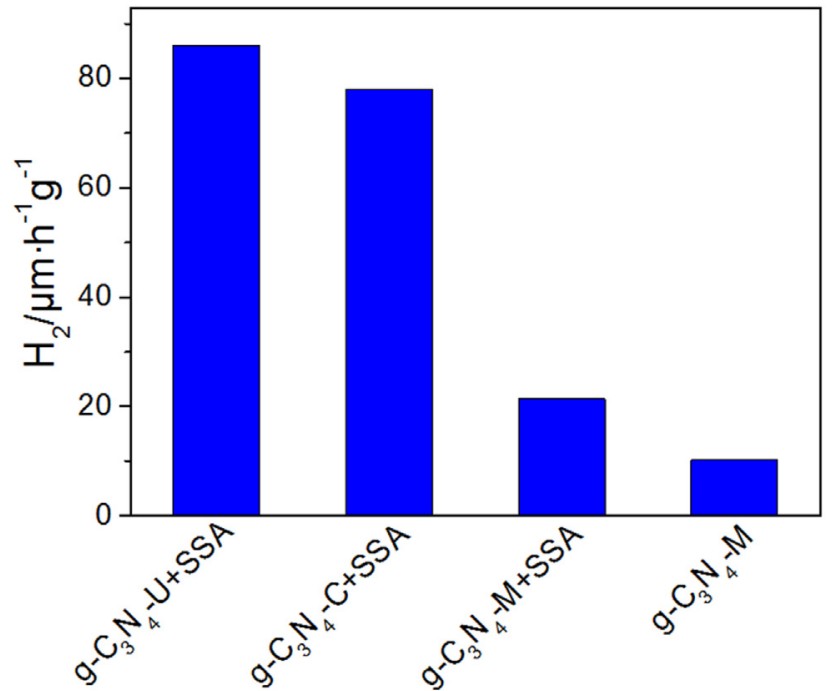

Fig. 8. Synergetic photocatalytic $\mathrm{H}_{2}$ evolution over g- $\mathrm{C}_{3} \mathrm{~N}_{4}$ derived from different precursors.

intimate relationship between the microstructure of carbon nitride and synergetic reaction performance. For high-efficiency photocatalysis, microstructure engineering of carbon nitride is crucial for synergetic photocatalytic applications.

The potential application of synergetic contaminant removal and energy production was also investigated, through coupling the reaction of SSA photodegradation with photocatalytic hydrogen production. We hoped to demonstrate a feasible way for solving the high energy consumption of wastewater treatment technologies. Fig. 8 shows hydrogen evolution over different carbon nitrides with 

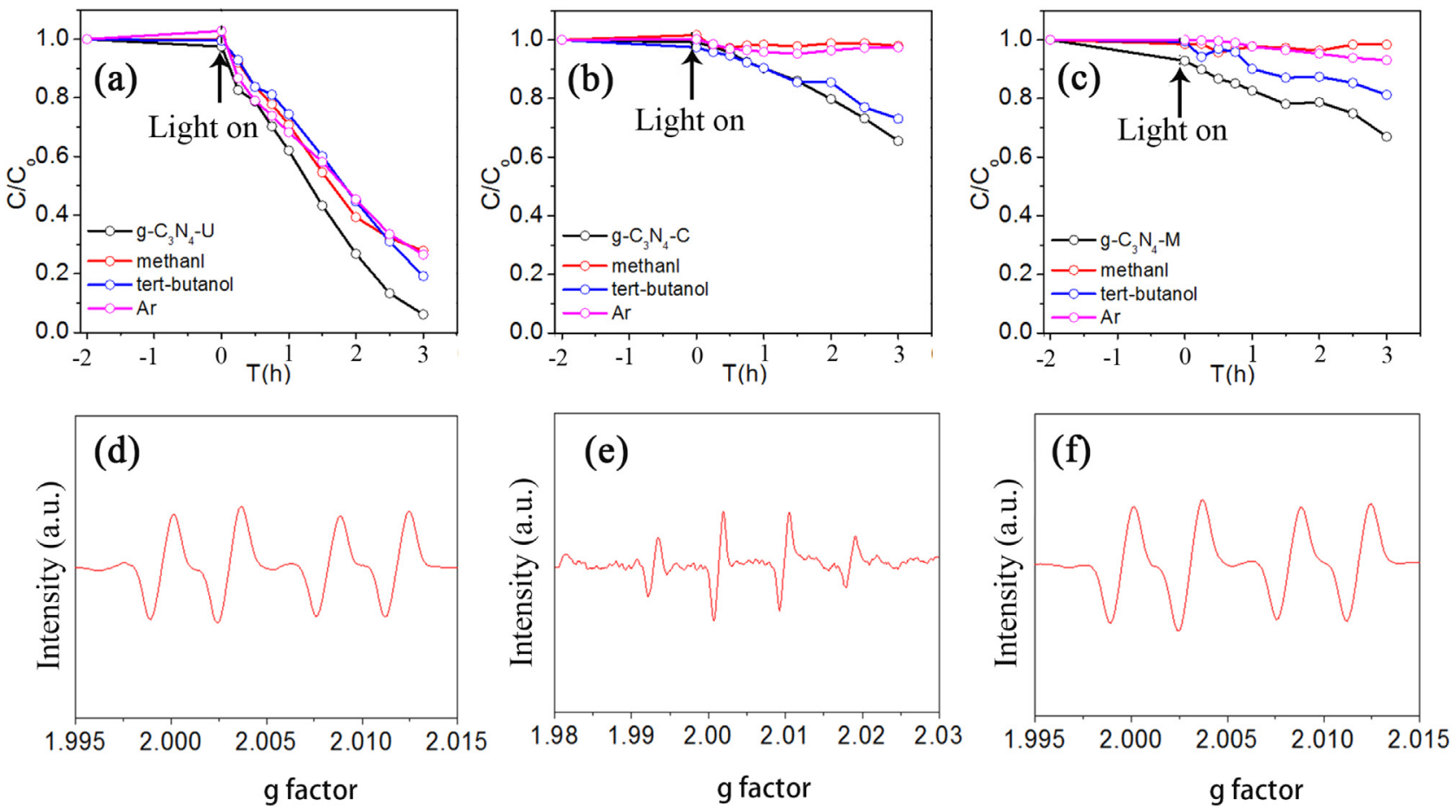

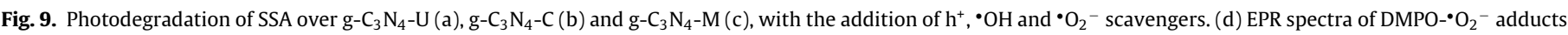

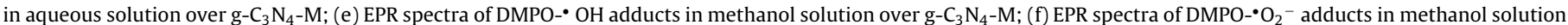
over $\mathrm{g}-\mathrm{C}_{3} \mathrm{~N}_{4}-\mathrm{C}$.

or without the addition of SSA. When the reactions of SSA oxidation and hydrogen evolution are combined, $\mathrm{g}-\mathrm{C}_{3} \mathrm{~N}_{4}-\mathrm{U}$ also presents the highest hydrogen evolution rate of $86 \mu \mathrm{mol} \mathrm{h}^{-1} \mathrm{~g}^{-1}$. This value is 4 times that of $\mathrm{g}_{-} \mathrm{C}_{3} \mathrm{~N}_{4}-\mathrm{M}\left(21.4 \mu \mathrm{mol} \mathrm{h}^{-1} \mathrm{~g}^{-1}\right)$, and 8 times higher than $\mathrm{g}-\mathrm{C}_{3} \mathrm{~N}_{4}-\mathrm{M}$ without SSA molecules. Due to the coexistence of nitrogen vacancies and oxygen doping in the microstructure, g$\mathrm{C}_{3} \mathrm{~N}_{4}-\mathrm{C}$ exhibited a hydrogen evolution rate of $78 \mathrm{~h}^{-1} \mathrm{~g}^{-1}$, which is about 4 times higher than the most commonly used g- $\mathrm{C}_{3} \mathrm{~N}_{4}-\mathrm{M}$. The coincident effects of carbon nitride microstructure on the efficiency of different synergetic reactions strongly confirm the above deductions.

\subsection{Mechanism of synergetic reaction: different roles of hydrogen bonds and structural defects}

Active species trapping experiments were carried out to reveal the effect of carbon nitride microstructure on synergetic reaction pathways. Generally, $\mathrm{h}^{+}, \bullet \mathrm{OH}$, and $\bullet^{-\mathrm{O}_{2}}{ }^{-}$are the possible reactive species for the photocatalytic degradation of organic pollutants, while $\mathrm{Cr}(\mathrm{VI})$ can be converted into $\mathrm{Cr}(\mathrm{III})$ in the presence of photoinduced electrons. To clarify the dominant active species for SSA degradation, different scavengers were added into the pollutant solution containing $40 \mathrm{mg} / \mathrm{L} \mathrm{SSA}$, using $50 \mathrm{mg}$ of different types of carbon nitride as photocatalysts. As shown in Fig. 9a, for g- $\mathrm{C}_{3} \mathrm{~N}_{4}-\mathrm{U}$ with its superior activity, only slightly decreased photodegradation efficiency was achieved when one kind of reactive species was inhibited with the addition of a specific scavenger. This indicated that $\mathrm{h}^{+}, \bullet \mathrm{OH}$, and $\bullet^{\bullet} \mathrm{O}_{2}{ }^{-}$contribute to the degradation of SSA equally. By contrast, the degradation of SSA over $\mathrm{g}-\mathrm{C}_{3} \mathrm{~N}_{4}-\mathrm{C}$ (Fig. 9b) and g- $\mathrm{C}_{3} \mathrm{~N}_{4}-\mathrm{M}$ (Fig. 9c) was significantly inhibited after the addition of methanol or purging with argon gas, suggesting that $\mathrm{h}+$ and $-\mathrm{O}_{2}{ }^{-}$are the dominant reactive species in the reactions. When tert-butanol was added, the photocatalytic activity of g- $\mathrm{C}_{3} \mathrm{~N}_{4}-\mathrm{M}$ decreased, but a negligible effect was observed for $g-C_{3} N_{4}-C$. This suggests that ${ }^{\bullet} \mathrm{OH}$ is not a reactive species for the oxidation reaction over $\mathrm{C}_{3} \mathrm{~N}_{4}-\mathrm{C}$, but does contribute to the photoactivity of $g-\mathrm{C}_{3} \mathrm{~N}_{4}-\mathrm{M}$. ESR spin-trapping (with DMPO) experiments further confirmed the generation of reactive radicals. As shown in Fig. 9d, a four-line ESR signal with an intensity ratio of $1: 1: 1: 1$ is clearly observed for g$\mathrm{C}_{3} \mathrm{~N}_{4}$-M upon irradiation, which is characteristic of the DMPO- ${ }^{\bullet} \mathrm{O}_{2}{ }^{-}$ adduct. ${ }^{\bullet} \mathrm{OH}$ radical is also detected with a characteristic $1: 2: 2: 1$ quadruplet (Fig. 9e). However, only strong signal corresponding to $-\mathrm{O}_{2}{ }^{-}$is detected during the photocatalytic reaction over $\mathrm{g}-\mathrm{C}_{3} \mathrm{~N}_{4}-\mathrm{C}$ (Fig. 9f), which is consistent with the above results.

Based on the above results, the relationship between carbon nitride microstructure and synergetic photocatalytic reactions was elucidated. Clearly, the type of precursor showed a significant influence on the microstructure of $\mathrm{C}_{3} \mathrm{~N}_{4}$. The high degree of polymerization of the urea precursor resulted in the lowest amount of hydrogen bonds and negligible structural defects. Using melamine and cyanamide as precursors facilitated the formation of nitrogen vacancies in carbon nitride, which could narrow the bandgap of the photocatalysts towards the visible light region. As a result, g$\mathrm{C}_{3} \mathrm{~N}_{4}-\mathrm{C}$ and g- $\mathrm{C}_{3} \mathrm{~N}_{4}$-M exhibited similar microstructures, except for differences in interlayer distances. The relatively larger interlayer distance of $\mathrm{g}-\mathrm{C}_{3} \mathrm{~N}_{4}-\mathrm{C}$ is beneficial for the formation of oxygendoped structures.

The microstructure of $g-\mathrm{C}_{3} \mathrm{~N}_{4}-\mathrm{U}$ had a significant impact on the efficiency of synergetic reactions. Generally, g- $\mathrm{C}_{3} \mathrm{~N}_{4}-\mathrm{U}$ with the narrowest bandgap exhibits the highest photoactivity. Therefore, light absorption ability can not be used to explain the differences in photocatalytic performance of carbon nitride. Surface area is usually considered as another important factor that might influence the reactivity of photocatalysts. It is possible that high surface area of $g$ $\mathrm{C}_{3} \mathrm{~N}_{4}$-U contributes to the photocatalytic reactions [43]. However, surface area seems not to be the determining factor, as $\mathrm{g}-\mathrm{C}_{3} \mathrm{~N}_{4}-\mathrm{M}$ with medium surface area presents the poorest performance. To support this, g- $\mathrm{C}_{3} \mathrm{~N}_{4}-\mathrm{U}$ with different surface area were also fabricated through changing heating temperatures. As can be seen from Fig. S5 and Fig. S6, increasing reaction temperature results 


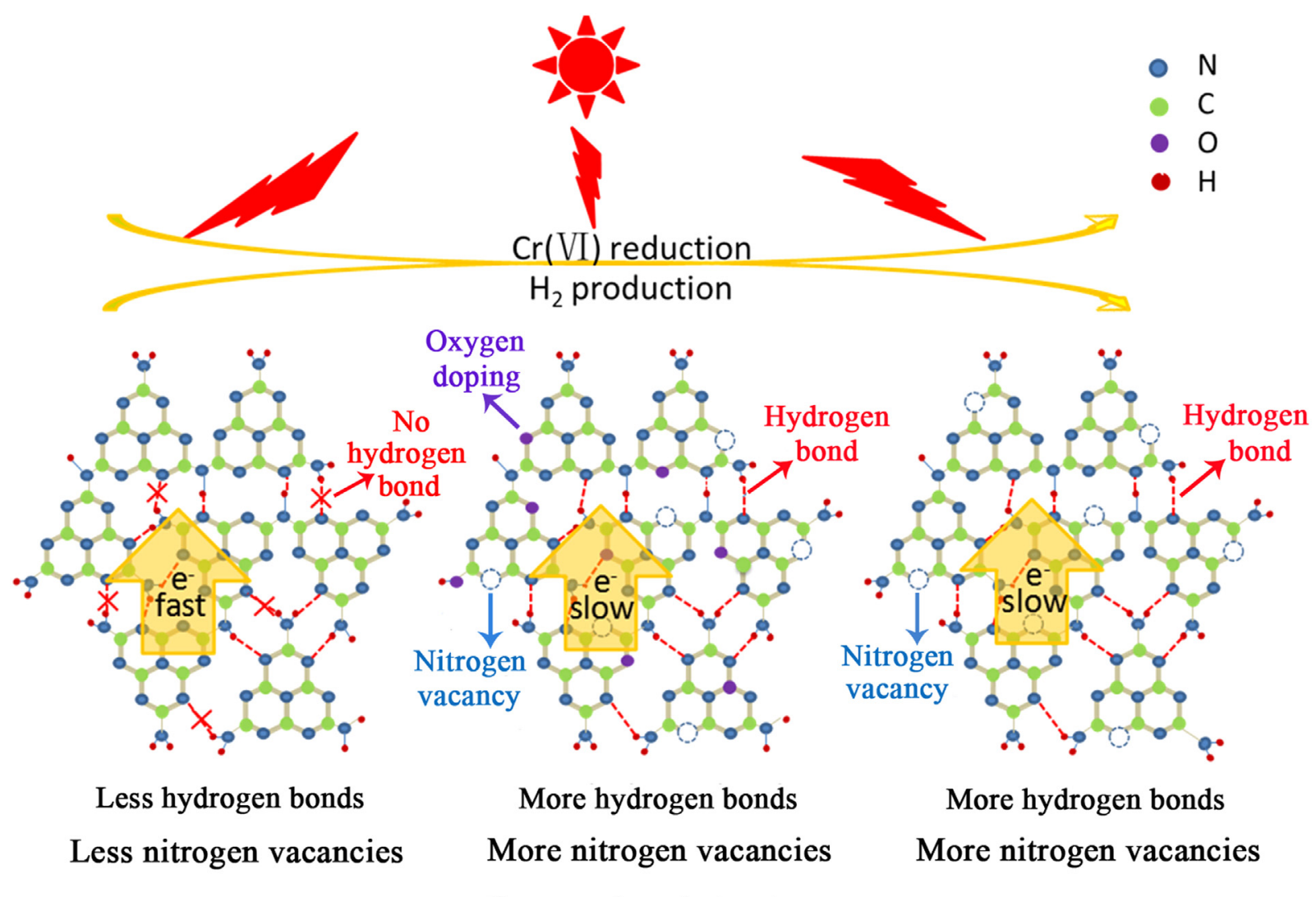

\section{Oxygen doped structures}

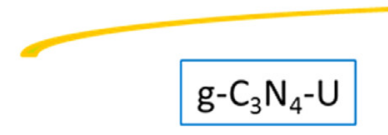

High activity
SSA oxidation

$$
\mathrm{g}-\mathrm{C}_{3} \mathrm{~N}_{4}-\mathrm{C}
$$

Medium activity

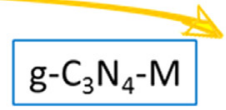

Low activity

Scheme 1. Schematic illustration of the mechanism for synergetic photocatalysis over $g-C_{3} N_{4}$ derived from different precursors.

in the increase of BET surface area. Surface area of $\mathrm{g}-\mathrm{C}_{3} \mathrm{~N}_{4}-\mathrm{U}-500$ $\left(45.1 \mathrm{~m}^{2} \mathrm{~g}^{-1}\right)$ is much lower than $\mathrm{g}-\mathrm{C}_{3} \mathrm{~N}_{4}-\mathrm{U}-550\left(95.1 \mathrm{~m}^{2} \mathrm{~g}^{-1}\right)$ and g- $\mathrm{C}_{3} \mathrm{~N}_{4}-\mathrm{U}-600\left(105.8 \mathrm{~m}^{2} \mathrm{~g}^{-1}\right)$. Interestingly, g- $\mathrm{C}_{3} \mathrm{~N}_{4}-\mathrm{U}-500$ exhibits superior ability for photoreduction of $\mathrm{Cr}(\mathrm{VI})$. The contradictory results indicate the impact of some other factors on the photoactivity of carbon nitride. After all, large quantity of photocatalysts $(50 \mathrm{mg}$ ) is necessary for removing pollutants in wastewater $(1 \mathrm{mg}$ $\mathrm{Cr}$ and $4 \mathrm{mg} \mathrm{SSA}$ ) and ultrasonic has been used to accelerate the surface adsorption. Hydrogen bonds, determined by the degree of polymerization, were found to be the dominant factor for the simultaneous and efficient removal of $\mathrm{Cr}(\mathrm{VI})$ and SSA. As shown in Scheme 1, the decrease of hydrogen bonds increased the number of reactive sites on the surface of $g-\mathrm{C}_{3} \mathrm{~N}_{4}$-U. Accordingly, transfer of photogenerated electrons across the interlayers was facilitated. It has been reported that reducing or oxidizing ability of photocatalysts is highly dependent with their band structures [44]. Due to the relatively higher conduction band of $\mathrm{g}-\mathrm{C}_{3} \mathrm{~N}_{4}-\mathrm{U}$, abundant electrons with stronger reducing abilities could significantly enhance the photoactivity for synergetic reactions, although it possesses weak light absorption and negligible defects compared to the other two precursors [43].

It has been reported that formation of nitrogen vacancies in $\mathrm{C}_{3} \mathrm{~N}_{4}$ could increase the visible light absorption and suppress charge recombination [37]. Here, it was found that the promotive effect of nitrogen vacancies on the synergetic reactions depended on the formation of oxygen-doped structures. Due to the difficulty in the diffusion of oxygen molecules between interlayers, oxygen doping was hard to achieve in $\mathrm{g}-\mathrm{C}_{3} \mathrm{~N}_{4}-\mathrm{M}$, even though sufficient nitrogen vacancies were present in the microstructure. Interestingly, the microstructure of $\mathrm{g}-\mathrm{C}_{3} \mathrm{~N}_{4}-\mathrm{C}$ was beneficial for oxygen doping. The role of doped oxygen as electron donor was credited for the moderate photoactivity of $\mathrm{g}-\mathrm{C}_{3} \mathrm{~N}_{4}-\mathrm{C}$ for synergetic reactions. This result was different from the conventional viewpoint that melamine is the preferred precursor for fabricating $\mathrm{C}_{3} \mathrm{~N}_{4}$ and the formation of vacancy defects can contribute to the enhancement of photoactivity. Due to the existence of abundant oxygen doped sites, $g-\mathrm{C}_{3} \mathrm{~N}_{4}-\mathrm{C}$ possesses much stronger ability for activating oxygen molecules around the surface of photocatalyst. This is in consistent with the dominant role of $\boldsymbol{}^{\mathrm{O}_{2}}{ }^{-}$for photocatalytic removal of SSA over g$\mathrm{C}_{3} \mathrm{~N}_{4}-\mathrm{C}$ (Fig. 8b). It seems that both photoreduction of $\mathrm{Cr}(\mathrm{VI})$ and photodegradation of SSA can be facilitated by the activation of oxygen molecules. On one hand, abundant ${ }^{\bullet} \mathrm{O}_{2}{ }^{-}$can contribute to the two-step indirect reduction of $\mathrm{Cr}(\mathrm{VI})$, with slow reaction kinetics. [45]. On the other hand, formation of reactive species results in the faster removal rate of $\mathrm{g}-\mathrm{C}_{3} \mathrm{~N}_{4}-\mathrm{C}$ than $\mathrm{g}-\mathrm{C}_{3} \mathrm{~N}_{4}$-M. Based on the radical trapping experiments, it can be deduced that ${ }^{\circ} \mathrm{O}_{2}{ }^{-}$directly participate into the photodegradation reactions for g- $\mathrm{C}_{3} \mathrm{~N}_{4}-\mathrm{C}$. Differently, the subsequent transformation of $\bullet^{\bullet} \mathrm{O}_{2}{ }^{-}$into ${ }^{\bullet} \mathrm{OH}$ is reasonable, as photogenerated holes in carbon nitride is not strong enough for oxidizing water into $\bullet \mathrm{OH}[46,47]$. It should be pointed out that 
partial oxygenation method has recently been used to improve photoactivity of carbon nitride [48]. When similar post-annealing procedures were used, the increased pollutant removal efficiency of oxygenated $\mathrm{g}-\mathrm{C}_{3} \mathrm{~N}_{4}-\mathrm{C}$ in Fig. $\mathrm{S} 7$ (synergetic reactions) and Fig. S8 (separate reactions) further confirms the facilitative effect of oxygen-doped structures $[49,50]$. In comparison, g- $\mathrm{C}_{3} \mathrm{~N}_{4}-\mathrm{M}$ with more hydrogen bonds, less oxygenation and higher valence band, exhibits the poorest performance for synergetic reactions. Thus, our finding should be valuable for the structural engineering of graphitic $\mathrm{C}_{3} \mathrm{~N}_{4}$ photocatalysts for high-performance applications.

\section{Conclusion}

In summary, the significant impact of carbon nitride microstructure on synergetic photocatalytic reactions was fundamentally investigated. Hydrogen bonds, related to the degree of polymerization, were found to be the dominant factor in the efficiency of synergetic reactions, rather than the generally investigated characteristics, such as light absorption and defects. Thermal polymerization of urea resulted in the smallest amount of hydrogen bonds and thereby significantly superior photoactivity for simultaneous removal of contaminants and energy production. Through comparing the effects of hydrogen bonds and structural defects, it was found that the formation of nitrogen vacancies and oxygen-doped structures were prerequisites for activating oxygen molecules, which demonstrated new insights into defect control of carbon nitride for improved photocatalytic performance. Based on the strategy of microstructure engineering, metal-free carbon nitride exhibited 3- and 8-fold improvements in removal rates of contaminants and hydrogen production rates compared to separate reactions. The comprehensive understanding of the relationship between $\mathrm{C}_{3} \mathrm{~N}_{4}$ microstructure and synergetic photoactivity provides guiding principles for the design of low-cost and high-performance metal-free photocatalysts for environmental remediation.

\section{Acknowledgments}

This work was supported by the National Natural Science Foundation of China (21401212, 51478455, 51225805). This project is also supported by the special fund from Key Laboratory of Drinking Water Science and Technology, Research Center for EcoEnvironmental Sciences, Chinese Academy of Sciences (Project No. 15Z05KLDWST)

\section{Appendix A. Supplementary data}

Supplementary data associated with this article can be found, in the online version, at http://dx.doi.org/10.1016/j.apcatb.2016. 11.022 .

\section{References}

[1] S. Cao, J. Low, J. Yu, M. Jaroniec, Adv. Mater. 27 (2015) 2150-2176.

[2] X. Wang, J.M. Carlsson, D. Kazunari, M. Antonietti, K. Maeda, A. Thomas, K. Takanabe, G. Xin, Nat. Mater. 8 (2009) 76-80.

[3] H. Yan, Chem. Commun. 48 (2012) 3430-3432.

[4] D.J. Martin, K. Qiu, A.S. Stephen, D.H. Albertus, X. Chen, Z. Guo, J. Tang, Angew Chem. Int. Ed. 53 (2014) 9240-9245.

[5] S.N. Habisreutinger, L. Schmidt-Mende, J.K. Stolarczyk, Angew. Chem. Int. Ed. 52 (2013) 7372-7408

[6] H. Sun, G. Zhou, Y. Wang, A. Suvorova, S. Wang, ACS Appl. Mater. Interfaces 6 (2014) 16745-16754.
[7] H. Zhang, L. Zhao, F. Geng, L.-H. Guo, B. Wan, Y. Yang, Appl. Catal. B-Environ. 180 (2016) 656-662.

[8] Y. Gong, M. Li, H. Li, Y. Wang, Green Chem. 17 (2015) 715-736.

[9] Z. Zhao, Y. Sun, F. Dong, Nanoscale 7 (2015) 15-37.

[10] B. Ai, X. Duan, H. Sun, X. Qiu, S. Wang, Catal. Today 258 (2015) 668-675.

[11] Y.P. Zhu, T.Z. Ren, Z.Y. Yuan, ACS Appl. Mater. Interfaces 7 (2015) $16850-16856$.

[12] X. Chen, J. Zhang, X. Fu, M. Antonietti, X. Wang, J. Am. Chem. Soc. 131 (2009) $11658-11659$

[13] G. Liu, P. Niu, C. Sun, S.C. Smith, Z. Chen, G.Q.M. Lu, H.-M. Cheng, J. Am. Chem. Soc. 132 (2010) 11642-11648.

[14] K. Sridharan, E. Jang, T.J. Park, Appl. Catal. B-Environ. 142-143 (2013) $718-728$.

[15] M. Yang, J. Liu, X. Zhang, S. Qiao, H. Huang, Y. Liu, Z. Kang, Phys. Chem. Chem. Phys. 17 (2015) 17887-17893.

[16] Y. Hong, Y. Jiang, C. Li, W. Fan, X. Yan, M. Yan, W. Shi, Appl. Catal. B-Environ. 180 (2016) 663-673.

[17] M. Sun, Q. Yan, T. Yan, M. Li, D. Wei, Z. Wang, Q. Wei, B. Du, RSC Adv. 4 (2014) 31019.

[18] W.J. Ong, L.K. Putri, L. Tan, S.P. Chai, S.T. Yong, Appl. Catal. B-Environ. 180 (2016) 530-543.

[19] M.K. Bhunia, K. Yamauchi, K. Takanabe, Angew. Chem. Int. Ed. 53 (2014) 11001-11005.

[20] K. Schwinghammer, M.B. Mesch, V. Duppel, C. Ziegler, J. Senker, B.V. Lotsch, J. Am. Chem. Soc. 136 (2014) 1730-1733.

[21] Y. Kang, Y. Yang, L.C. Yin, X. Kang, G. Liu, H.M. Cheng, Adv. Mater. 27 (2015) 4572-4577.

[22] V. W.-h. Lau, M.B. Mesch, V. Duppel, V. Blum, J. r. Senker, B.V. Lotsch, J. Am. Chem. Soc. 137 (2015) 1064-1072.

[23] P. Niu, L. Yin, Y. Yang, G. Liu, H. Cheng, Adv. Mater. 26 (2014) 8046-8052

[24] Y. Cui, G. Zhang, Z. Lin, X. Wang, Appl. Catal. B-Environ. 181 (2016) 413-419.

[25] A. Tanaka, K. Nakanishi, R. Hamada, K. Hashimoto, H. Kominami, ACS Catal. 3 (2013) 1886-1891

[26] G. Srinivas, V. Krungleviciute, Z. Guo, T. Yildirim, Energy Environ. Sci. 7 (2014) 335-342.

[27] X. Zong, H. Chen, B. Seger, T. Pedersen, M.S. Dargusch, E.W. McFarland, C. Li, L. Wang, Energy Environ. Sci. 7 (2014) 3347-3351.

[28] A.E. Giannakasa, M. Antonopoulou, C. Daikopoulos, Y. Deligiannakis, I. Konstantinou, Appl. Catal. B-Environ. 184 (2016) 44-54.

[29] J. Zhu, P. Xiao, H. Li, S.A. Carabineiro, ACS Appl. Mater. Interfaces 6 (2014) 16449-16465.

[30] C. Wang, X. Zhang, H. Liu, X. Li, W. Li, H. Xu, J. Hazard. Mater. 163 (2009) 1101-1106.

[31] Q. Han, B. Wang, J. Gao, Z. Cheng, Y. Zhao, Z. Zhang, L. Qu, ACS Nano 10 (2016) 2745-2751.

[32] M.K. Bhunia, S. Melissen, M.R. Parida, P. Sarawade, J.-M. Basse, D.H. Anjum, O.F. Mohammed, P. Sautet, T.L. Bahers, K. Takanabe, Chem. Mater. 27 (2015) 8237-8247.

[33] F. Chen, X. Zhao, H. Liu, J. Qu, Appl. Catal. B-Environ. 158-159 (2014) 85-90.

[34] Y. Kang, Y. Yang, L.C. Yin, X. Kang, L. Wang, G. Liu, H.M. Cheng, Adv. Mater (2016), http://dx.doi.org/10.1002/adma.201601567.

[35] R. Chen, J. Zhang, Y. Wang, X. Chen, J.A. Zapien, C.S. Lee, Nanoscale 7 (2015) 17299-17305.

[36] J. Li, B. Shen, Z. Hong, B. Lin, B. Gao, Y. Chen, Chem. Commun. 48 (2012) 12017-12019.

[37] F. Cheng, J. Yan, C. Zhou, B. Chen, P. Li, Z. Chen, X. Dong, J. Colloid Interface Sci. 468 (2016) 103-109.

[38] Q. Gu, Z. Gao, H. Zhao, Z. Lou, Y. Liao, C. Xue, RSC Adv. 5 (2015) 49317-49325.

[39] Q. Liang, Z. Li, Z. Huang, F. Kang, Q. Yang, Adv. Funct. Mater. 25 (2015) 6885-6892.

[40] S. Li, G. Dong, R. Hailili, L. Yang, Y. Li, F. Wang, Y. Zeng, C. Wang, Appl. Catal. B-Environ. 190 (2016) 26-35.

[41] F. Dong, M. Ou, Y. Jiang, S. Guo, Z. Wu, Ind. Eng. Chem. Res. 53 (2014) 2318-2330.

[42] Q. Liang, Z. Li, Z. Huang, F. Kang, Q. Yang, Adv. Func. Mater. 25 (2015) 6885-6892.

[43] F. Dong, Z. Zhao, T. Xiong, Z. Ni, W. Zhang, Y. Sun, W. Ho, ACS Appl. Mater. Interfaces 5 (2013) 11392-11401.

[44] H. Kisch, Angew. Chem. Int. Ed. 52 (2013) 812-847.

[45] G. Dong, L. Zhang, J. Phys. Chem. C 117 (2013) 4062-4068.

[46] H. Li, Shiyu Gan, Haoyu Wang, Dongxue Han, Li Niu, Adv. Mater. 27 (2015) 6906-6913.

[47] F. Dong, Z. Wang, Y. Li, W. Ho, S. Lee, Environ. Sci. Technol. 48 (2014) $10345-10353$.

[48] X. She, J. Wu, J. Zhong, H. Xu, Y. Yang, R. Vajtai, J. Lou, Y. Liu, D. Du, H. Li, P. Ajayan, Nano Energy 27 (2016) 138-146.

[49] L. Xu, W. Huang, L. Wang, Z. Tian, W. Hu, Y. Ma, X. Wang, A. Pan, G. Huang, Chem. Mater. 27 (2015) 1612-1621.

[50] S. Guo, Y. Zhu, Y. Yan, Y. Min, J. Fan, Q. Xu, Appl. Catal. B-Environ. 185 (2016) 315-321. 